\title{
The relationship between bupropion and suicide in post-mortem investigations
}

\section{Kriikku, Pirkko}

2016-09

Kriikku , P \& Ojanpera , I 2016 , ' The relationship between bupropion and suicide in post-mortem investigations ' , Forensic Science International , vol. 266 , pp. 343-348 . https://doi.org/10.1016/j.forsci

http://hdl.handle.net/10138/228782

https://doi.org/10.1016/j.forsciint.2016.06.026

publishedVersion

Downloaded from Helda, University of Helsinki institutional repository.

This is an electronic reprint of the original article.

This reprint may differ from the original in pagination and typographic detail.

Please cite the original version. 


\title{
The relationship between bupropion and suicide in post-mortem investigations
}

\author{
Pirkko Kriikku* , Ilkka Ojanperä \\ Department of Forensic Medicine, University of Helsinki, PO Box 40, FI-00014 Helsinki, Finland
}

\section{A R T I C L E I N F O}

\section{Article history:}

Received 24 December 2015

Received in revised form 13 June 2016

Accepted 17 June 2016

Available online 23 June 2016

\section{Keywords:}

Forensic toxicology

Bupropion

Antidepressant

Suicide

Fatal poisoning

Postmortem

\begin{abstract}
A B S T R A C T
We reviewed the 33727 postmortem toxicology investigations performed in Finland over a period of 5 years (2009-2013) and identified those in which the antidepressant bupropion was detected. Cases positive for other antidepressant drugs were reviewed for comparison.

The postmortem toxicological examination included, in all cases, the routine screening and quantification of hundreds of drugs and poisons using quality-controlled methods.

Bupropion was detected in 65 cases. A large proportion of the bupropion-positive deaths resulted from suicide (55\%). In fatal poisoning cases found positive for bupropion, the proportion of suicide was even higher (77\%). The measured median bupropion postmortem blood concentration $(0.69 \mathrm{mg} / \mathrm{L}) \mathrm{was}$ markedly higher than the normal therapeutic range in plasma in the treatment of depression (up to $0.1 \mathrm{mg} / \mathrm{L})$ and even higher in fatal bupropion poisonings $(13 \mathrm{mg} / \mathrm{L})$.

Only $14 \%$ of the deceased positive for bupropion were estimated to be drug abusers. However, nearly all of the drug abuse cases were from the last year of the study (2013), indicating a recent increase of the use of bupropion among drug abusers and possibly even abuse of bupropion itself.

Suicide victims positive for bupropion were younger than those who died with other antidepressant drugs in their blood. In addition, the percentage of fatal poisonings among bupropion-positive postmortem cases was higher than among the users of other antidepressant drugs. Suicide was significantly more common among the deceased positive for bupropion than among users of other antidepressant drugs.

An unknown degree of bupropion degradation before the assay and post-mortem redistribution of bupropion may have impacted the measured levels. Nonetheless, all post-mortem concentrations of bupropion were elevated and especially high concentrations were detected in suicides.
\end{abstract}

(C) 2016 Elsevier Ireland Ltd. All rights reserved.

\section{Introduction}

Bupropion belongs to the chemical class of synthetic cathinones; a group of abused novel psychoactive substances that have gained widespread publicity over the last decade. Synthetic cathinones are structurally related to cathinone, the principal active compound of khat (Fig. 1). In Finland, the most prevalent of the abused synthetic cathinones have been MDPV, $\alpha$-PVP and methylone (Fig. 1), all of which are currently banned.

Bupropion (Fig. 1) is approved for medicinal use for the treatment of depression and as a smoking cessation aid, which makes its user profile very different from that of the other synthetic cathinones which have no medicinal use. Bupropion (also known as amfebutamone) is marketed under the trade

\footnotetext{
* Corresponding author.

E-mail address: pirkko.kriikku@helsinki.fi (P. Kriikku).
}

names Zyban, Voxra and Wellbutrin. Besides its main indications, bupropion has been demonstrated to be effective in the treatment of attention-deficit/hyperactivity disorder (ADHD) [1], chronic fatigue [2], and in the treatment of cocaine dependence [3]. It is a weak norepinephrine-dopamine reuptake inhibitor (NDRI) but the complete mechanism of action is still not completely known [4]. Bupropion undergoes extensive hepatic metabolism to three metabolites: hydroxybupropion, threobupropion, and erythrobupropion. Less than $1 \%$ of the parent compound is found in urine [5]. It has also been reported that bupropion is quite unstable in stored non-frozen plasma

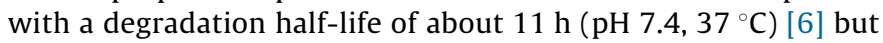
it is stable in plasma frozen at $-22^{\circ} \mathrm{C}$ or $-65^{\circ} \mathrm{C}$ and survives several freeze/thaw cycles [7].

The typical therapeutic dose of bupropion is $150-300 \mathrm{mg}$ per day. Plasma levels in the treatment of depression are in the range of 0.025-0.1 mg/L. The elimination half-life of the drug in chronic use is $21 \pm 9 \mathrm{~h}$. Steady state plasma concentration after the ingestion of 
<smiles>CC(N)Cc1ccccc1</smiles>

AMPHETAMINE<smiles>CC(N)C(=O)c1ccccc1</smiles>

CATHINONE<smiles>CC(NC(C)(C)C)C(=O)c1cccc(Cl)c1</smiles><smiles>CCCC(C(=O)c1ccc2c(c1)OCO2)N(CC)CC</smiles>

MDPV<smiles>CCCCCCCC(C)NC</smiles>

METHYLONE<smiles>CCCC(C(=O)c1ccccc1)N1CCCC1</smiles>

ALPHA-PVP

Fig. 1. Chemical structures of amphetamine, cathinone and some of the synthetic cathinones.

therapeutic doses of immediate release products is achieved within 8 days $[8,9]$.

Although originally considered unlikely $[10,11]$, some recent reports of bupropion abuse, especially among young adults and adolescents, have been published. At present, ten peer-reviewed articles in which "bupropion abuse" is mentioned in the title of the article can be found in PubMed (accessed 11 December 2015) $[10,12-20]$. Half of these articles were published in the last 3 years.

Antidepressant drugs are widely prescribed for the treatment of depression although for many of them the mechanism by which they exert their therapeutic effects is not well understood. The consumption of antidepressants has increased steadily over recent years in many countries and in Finland the consumption in 2013, measured as the number of defined daily doses (DDD) sold by drug wholesalers to pharmacies and hospitals per 1000 inhabitants per day, was above that of the OECD mean (69 vs. 58) [21]. The DDD is the assumed average maintenance dose per day for a drug used for its main indication in adults (www.whocc.no/ddd/definition_and_ general_considera/).

The risk of suicide is greatly affected by various biological, psychological, social, and cultural factors. Depression and other mood disorders markedly increase the risk of self-destructive behaviours [22]. Many studies have shown that the class of antidepressant drugs most commonly prescribed for depression in Finland, the selective serotonin re-uptake inhibitors (SSRI), either reduce the risk of suicide [23-25] or at least do not increase the risk of suicide in the first few weeks of treatment, a problem that has been shown for other classes of antidepressants [26].

For individuals abusing drugs, the most common manner of death is generally unintentional (accidental) rather than suicide $[27,28]$. However, previous studies have suggested an increased prevalence of suicides among deceased positive for synthetic cathinones [29,30]. Additionally, despite its reputation as safe drug [1], in 2004 the US Food and Drug Administration (FDA) issued a public health advisory regarding worsening depression and suicidality in paediatric and adult patients being treated with bupropion and some other newer antidepressants [31]. Further, in 2009 an FDA Post Marketing Review found evidence of suicide and suicidal thoughts among some patients treated with bupropion for smoking cessation [32].

Given these circumstances, we sought to utilize the large registry of forensic toxicology data available in Finland to investigate a possible association between the use of bupropion and suicide. We have reviewed the postmortem cases positive for bupropion in Finland during a 5-year period (2009-2013) in terms of toxicological findings, cause and manner of death, and demographic information. For comparison, we also looked at the suicide rate among those postmortem cases positive for other antidepressant drugs over the same time period.

\section{Material and methods}

In Finland, all sudden and unexpected deaths are required by law to have a medico-legal investigation, initiated by the police and conducted by a forensic pathologist. According to the law, a medico-legal investigation into the cause of death is to be performed when (1) death is caused or suspected to be caused by crime, injury, suicide, poisoning, occupational disease or medical treatment, or, (2) death has not been caused by a disease, or, (3) during the latest illness the deceased has not been treated by a doctor, or (4) death is otherwise unexpected [33].

As a result of this law, approximately $18-20 \%$ of all deceased undergo a medico-legal investigation. In most medico-legal cases, comprehensive postmortem toxicology is also performed. During the study period, the number of postmortem toxicology cases was 33727 , corresponding to about $13 \%$ of all deaths.

Autopsies took place on average 6 days after death. Once the cadaver reached the department of forensic medicine it was stored at $+4-8{ }^{\circ} \mathrm{C}$ but the conditions prior that may have varied considerably depending on the time interval from death to the time when the body was found. Blood samples were collected during the autopsy and stored in tubes contain sodium fluoride as preservative at $+5{ }^{\circ} \mathrm{C}$ until analysed. The interval between sample collection and analysis was in most cases 1-5 days.

The postmortem toxicological examination included the screening and quantification of hundreds of drugs and poisons by quality-controlled methods. Specifically, bupropion and the other antidepressant drugs were screened in urine by ultra-high performance liquid chromatography coupled with high-resolution time-of-flight mass spectrometry [34,35]. The quantification of the substances in blood was performed using dual-column gas chromatography with nitrogen-phosphorus detections (GC-NPD) [36]. The limit of quantification (LOQ) in blood was $0.10 \mathrm{mg} / \mathrm{L}$ for 
Table 1

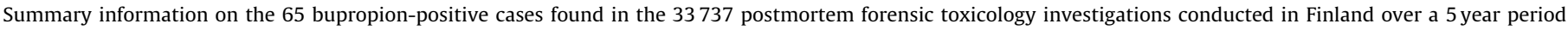
(2009-2013).

\begin{tabular}{|c|c|c|c|c|c|c|c|c|c|c|c|c|c|c|}
\hline & \multirow[b]{2}{*}{$N$} & \multicolumn{2}{|c|}{ Suicide } & \multicolumn{2}{|c|}{ Illness } & \multicolumn{2}{|c|}{ Accident } & \multicolumn{2}{|c|}{ Unknown } & \multicolumn{2}{|l|}{ Age } & \multirow{2}{*}{$\begin{array}{l}\text { Males } \\
\%\end{array}$} & \multicolumn{2}{|c|}{ Blood alcohol (g/kg) } \\
\hline & & $N$ & $(\%)$ & $N$ & $(\%)$ & $N$ & $(\%)$ & $N$ & $\%$ & Mean & Range & & Median & Range \\
\hline All buproprion positive cases & 65 & 36 & $(55)$ & 16 & $(25)$ & 8 & $(12)$ & 5 & $(8.0)$ & 47 & $19-83$ & 65 & 1.6 & $0.32-3.1$ \\
\hline \multicolumn{15}{|l|}{ 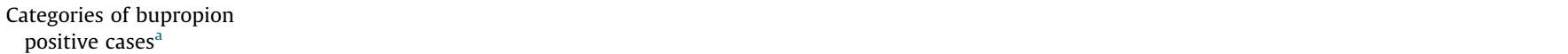 } \\
\hline Drug abuse cases & 9 & 4 & $(44)$ & 2 & $(22)$ & 3 & (33) & - & - & 36 & $28-44$ & 100 & 1.1 & $0.79-2.0$ \\
\hline Fatal poisonings & 30 & 25 & $(83)$ & - & - & 3 & $(10)$ & 2 & $(6.7)$ & 44 & $19-70$ & 53 & 1.5 & $0.32-2.9$ \\
\hline $\begin{array}{l}\text { Bupropion primary } \\
\text { cause of death }\end{array}$ & 20 & 19 & $(95)$ & - & - & 1 & $(5)$ & - & - & 44 & $19-70$ & 60 & 1.7 & $0.32-2.8$ \\
\hline $\begin{array}{l}\text { Bupropion } \\
\text { monointoxications }\end{array}$ & 5 & 5 & $(100)$ & - & - & - & - & - & - & 41 & $26-52$ & 60 & & \\
\hline Other than poisonings & 35 & 11 & $(31)$ & 16 & $(46)$ & 5 & $(14)$ & 3 & $(8.6)$ & 48 & $20-83$ & 74 & 1.5 & $0.33-3.1$ \\
\hline
\end{tabular}

a Individual cases can appear in more than one category.

bupropion, amitriptyline, citalopram and venlafaxine and $0.05 \mathrm{mg} /$ L for mirtazapine.

All the results of the postmortem toxicology examinations as well as the results of other tests and analyses, background information provided by the police that had initiated the medicolegal cause-of-death investigation, and the cause and manner of death defined by the forensic pathologist were registered in the laboratory database. In cases of fatal poisonings, the forensic pathologist had determined the cause of death.

All statistical analyses were carried out using IBM SPSS software (version 23.0) using the Mann-Whitney $U$ test.

\section{Results}

There were 65 cases positive for bupropion during 2009-2013 in the postmortem toxicology database which contained 33727 cases in total. Details of these cases are presented in Table 1.

Bupropion was present in 30 cases in which poisoning was determined to be the cause of death. Of these, 25 (83\%) were suicides and the rest unintentional overdose deaths or cases where the manner of death was unknown. Bupropion was the primary drug finding in 20 of the fatal poisonings and assumed to be a major factor in the fatality in these cases. Of these 20 fatal bupropion poisonings, all except one were suicides (95\%); significantly higher than the proportion of suicides in all fatal drug poisonings in Finland in 2013 (41\%) (Mann-Whitney, $p<0.001$ ). The mean age in bupropion-positive suicides was 43 years and for all fatal drug poisonings in 2013 the mean age was 46 years.

Of the 20 fatal poisonings in which bupropion was considered by the forensic pathologist to be a major factor, five (25\%) were bupropion mono-intoxications. In the rest, the fatal poisoning was considered to be caused by bupropion in combination with alcohol, benzodiazepines, or other medicinal drugs.

In 55 out of 65 bupropion-positive cases (85\%), there was a quantitative result available for bupropion in peripheral blood. In the remaining 10 cases, bupropion was only detected in urine or the concentration in blood was below the LOQ $(0.1 \mathrm{mg} / \mathrm{L})$. The blood concentrations of bupropion in different manners of death and other groups are given in Table 2 .

In one of the suicidal bupropion poisonings, in which the postmortem blood bupropion concentration was $6.5 \mathrm{mg} / \mathrm{L}$, there was an ante-mortem serum sample available taken on arrival at the hospital about $5 \mathrm{~h}$ before the death of the patient. In the antemortem serum sample the bupropion concentration was $17 \mathrm{mg} / \mathrm{L}$. In this case, despite of having been treated for the intoxication, the patient died and the cause of death was determined to be fatal intoxication by bupropion and lithium.
Of the cases positive for bupropion $(N=65)$, in nine (14\%) there was background information on drug abuse or there were other findings that could be attributed to drug abuse, such as findings of illegal drugs. Of these nine cases, seven (78\%) were from 2013. The mean age in the drug abuse cases was 36 years which is significantly lower than in all bupropion-positive cases (46 years) (Mann-Whitney, $p=0.018$ ). Of the nine drug abuser cases, in four (44\%) the manner of death was determined to be suicide. In the whole postmortem toxicology material from 2013 there were 352 cases in which the findings or the background information indicated that the deceased had been abusing drugs. Of these cases, $19 \%$ were suicides.

\subsection{Antidepressants}

There were a total of 7360 antidepressant (ATC code N06A) findings (including the bupropion-positive cases) in 6187 separate postmortem cases in the 2009-2013 study period. Bupropion was found in $1.1 \%$ of the antidepressant-positive postmortem cases. In terms of sales statistics, bupropion accounted for $0.72 \%$ of the sales of antidepressants in Finland calculated as a mean over the five studied years. The yearly sales of bupropion expressed as DDD per 1000 inhabitants per day increased during the study period from 0.08 in 2009 to 1.13 in 2013 (source: Finnish Medicines Agency, Drug Sales Register).

Of all antidepressant-positive deaths, $43 \%$ were caused by natural causes, $26 \%$ by accident and $24 \%$ by suicide. The four most common antidepressants in suicide cases were citalopram, mirtazapine, venlafaxine and amitriptyline. Bupropion was detected in $2.4 \%$ of the suicide cases positive for antidepressant drugs. The manners of death for bupropion and the four most common antidepressants are illustrated in Fig. 2. The proportion of suicides in bupropion-positive cases (55\%) was significantly higher than in the cases positive for other antidepressant drugs

Table 2

The mean, median and interquartile range (IQR) values for bupropion concentration in the blood of various groups of bupropion-positive fatalities.

\begin{tabular}{lccl}
\hline & $\begin{array}{l}\text { Mean } \\
(\mathrm{mg} / \mathrm{L})\end{array}$ & $\begin{array}{l}\text { Median } \\
(\mathrm{mg} / \mathrm{L})\end{array}$ & $\begin{array}{l}\mathrm{IQR} \\
(\mathrm{mg} / \mathrm{L})\end{array}$ \\
\hline All cases $(N=55)$ & 9.4 & 0.69 & $0.36-5.4$ \\
All suicides $(N=32)$ & 16 & 1.9 & $0.39-22$ \\
Suicides by bupropion $(N=19)$ & 26 & 15 & $3.4-41$ \\
All fatal poisonings $(N=30)$ & 17 & 2.4 & $0.55-29$ \\
Fatal bupropion poisonings $(N=20)$ & 25 & 13 & $2.5-41$ \\
Other causes $($ not poisonings $)(N=25)$ & 0.73 & 0.42 & $0.35-0.79$ \\
Drug abusers $(N=6)$ & 8.7 & 0.34 & $0.20-0.94$ \\
\hline
\end{tabular}

Note: In 10 of the 65 bupropion-positive fatalities the drug was only detected in urine or the blood concentration was below the LOQ of the assay and these cases have been excluded from the table. 


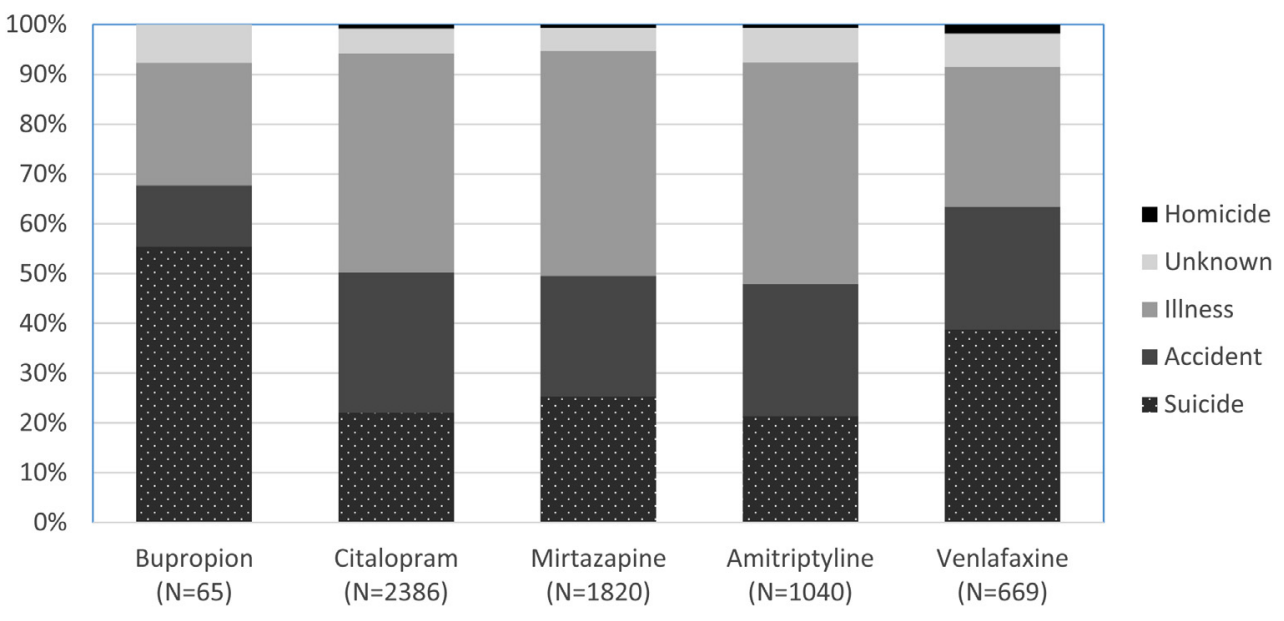

Fig. 2. Proportions of different manners of death in cases positive for bupropion and some other antidepressants.

(citalopram 22\%, mirtazapine 25\%, amitriptyline 21\%, venlafaxine 39\%) (Mann-Whitney, $p<0.001$ ).

The mean age of the deceased in all antidepressant-positive cases was 56 years and in antidepressant-positive suicides it was 48 years. The mean age of the deceased positive for bupropion was significantly lower (47 years) than the mean age of deceased positive for other antidepressants (Mann-Whitney, $p<0.001$ ). For individual antidepressant drugs, except for trazodone, the mean age in suicides was on average 6 years lower than in all cases positive for the drug (trazodone all cases: 56 years, suicides: 57 years). The age differences (all cases vs. suicides) for bupropion and some other antidepressant drugs are illustrated in Table 3.

Of the cases positive for any antidepressant drug in the study period, 1530 were fatal drug poisonings (medicinal or illicit drugs). In $33 \%$ of the fatal poisonings positive for antidepressants, the most relevant finding was an antidepressant drug. Citalopram was the most common antidepressant finding in fatal poisonings $(N=520)$. The proportions of some antidepressants as the most important finding in fatal poisonings are illustrated in Table 4 .

Table 3

Mean ages of cases positive for bupropion and some other antidepressant drugs and for those cases in which the manner of death was suicide.

\begin{tabular}{lclll}
\hline & $\begin{array}{l}\text { Number of } \\
\text { antidepressant } \\
\text { positive cases }\end{array}$ & $\begin{array}{l}\text { Proportion of } \\
\text { suicides }\end{array}$ & Mean age & \\
\cline { 3 - 5 } & & & All cases & Suicides \\
\hline Bupropion & 65 & $55 \%$ & 46.5 & 43.1 \\
Citalopram & 2386 & $22 \%$ & 56.5 & 47.9 \\
Mirtazapine & 1820 & $25 \%$ & 57.8 & 51.7 \\
Amitriptyline & 1040 & $21 \%$ & 56.6 & 50.6 \\
Venlafaxine & 669 & $39 \%$ & 49.0 & 44.8 \\
Trazodone & 47 & $36 \%$ & 55.9 & 56.8 \\
\hline
\end{tabular}

Table 4

Proportion of fatal poisonings in cases positive for bupropion and the four most common antidepressant drugs in which the antidepressant was identified as the major finding.

\begin{tabular}{lcc}
\hline & $\begin{array}{l}\text { Detected in fatal } \\
\text { poisonings }(N)\end{array}$ & $\begin{array}{l}\text { Primary finding } \\
\text { in fatal poisonings }\end{array}$ \\
\hline Bupropion & 30 & $67 \%$ \\
Citalopram & 520 & $8 \%$ \\
Mirtazapine & 370 & $14 \%$ \\
Amitriptyline & 345 & $38 \%$ \\
Venlafaxine & 250 & $34 \%$ \\
\hline
\end{tabular}

\section{Discussion}

The Finnish postmortem toxicology database forms an extensive source of valuable data due to the high percentage of fatalities that undergo medico-legal cause-of-death investigations in Finland. According to an earlier study, a medico-legal autopsy is performed in $87.2 \%$ of all unintentional injury deaths, in $98.3 \%$ of homicides and in $99.5 \%$ of suicides [37]. Thus, even though some deaths of individuals using antidepressant drugs will not have undergone a medico-legal investigation, the proportion of such cases is small and it is reasonable to assume that the data reported here are a realistic representation of the population of antidepressant-positive deaths as a whole.

Our analysis of this database revealed that suicide was the most common manner of death among bupropion-positive fatalities. In Finland, bupropion was approved for smoking cessation in 2003 and for treatment of depression in 2010. Therefore, the deceased in the study period (2009-2013) could have had the drug prescribed for either indication, off label prescriptions or been abusing it without prescription. Complete prescription information (e.g., indication, dose, duration of treatment) was not available to us so in order to obtain some perspective on the association of bupropion with suicide we chose to compare the bupropion data with that of other drugs classified as antidepressants, recognizing that for a minor proportion of the cases the drugs could have been prescribed for other indications. The suicide rate in bupropion-positive fatalities was significantly higher than that in fatalities positive for other antidepressant drugs. Bupropion-positive fatalities were also younger than fatalities positive for other antidepressants.

Bupropion was the most commonly encountered synthetic cathinone in the study period in Finland and is the only one in medicinal use. The majority of suicides and accidents of individuals positive for bupropion in this study were fatal poisonings - which differs from a previous study in which synthetic cathinones were more prevalent in mechanical suicides than in fatal poisonings [29]. We can offer no explanation for this apparent difference.

Interpretation of the observed association of the presence of bupropion in postmortem blood with suicides is complicated by a number of limitations of this study. The principles of prescribing antidepressants to depressed patients probably vary greatly among physicians and in some cases bupropion may have been used by non-depressed patients as a smoking cessation aid. Unfortunately, our source material did not include sufficient information on the mental or medical history of the deceased to establish whether the patients receiving bupropion shared some 
common features in their condition which may have led to them being prescribed bupropion or to be at increased risk while taking it. Bupropion is not structurally related to any of the other antidepressants included in the study and its mechanism of action in the treatment of depression is not entirely known. Nonetheless, it has been suspected of sharing with other classes of antidepressants some risk of increased suicides [31]. Therefore, the association of bupropion with suicides is not unprecedented. However, the higher incidence of suicides compared to other antidepressants in this material is contrary to other reports [24,26] but could be related to the very high levels observed in our material.

The percentage of bupropion-positive cases with evidence of drug abuse was low although our results suggest an increase in the number of bupropion-positive drug abuse cases over the studied years. It has been noted by some physicians working in drug rehabilitation that patients ask for bupropion as part of their treatment and admit to taking it to gain similar effects to those provided by the more established abused drugs [38]. This anecdotal information, together with published reports on abuse cases, suggests that users of illegal drugs find bupropion attractive as a part of the spectrum of psychoactive substances they abuse. However, only a minority of the bupropion-positive cases in our study could be attributed to drugs abuse (14\%), and in most of these, the manner of death was other than suicide. Thus, most of the suicides associated with the use of bupropion were in a population with no evidence of drug abuse which raises concern of the possible effects of the drug in medical use.

In our study, the median bupropion concentration in fatal poisonings in which bupropion was the major finding was $13 \mathrm{mg} / \mathrm{L}$ which is within the range reported by Spiller et al. who found concentrations ranging from 3.1 to $>20 \mathrm{mg} / \mathrm{L}$ in the five cases of their study [39]. In other studies of fatal bupropion poisonings, considerably lower concentrations have been measured [40-43]. In most of the cases in our study, bupropion was detected among multiple other psychoactive drugs or alcohol. Previous research has indicated that other drugs that affect the central nervous system may exacerbate the neurotoxic effects of bupropion [44].

Bupropion is unstable in aqueous solutions $[6,45]$ but is stable in frozen plasma [7]. To our knowledge, the stability of bupropion has not been studied in postmortem whole blood or urine and such test were not performed as a part of our study. Furthermore, no information on postmortem redistribution of bupropion is available. The postmortem interval in Finland is on average 6 days. In our study, the blood and urine samples were collected during the autopsy and were thereafter stored at $+5{ }^{\circ} \mathrm{C}$ using sodium fluoride as a preservative. The analysis was performed within 1-5 days of blood collection. Therefore, it is not possible to extrapolate from the measured concentrations in postmortem blood to the concentrations at time of death. However, some degradation of bupropion will have taken place between the time of death and measurement of bupropion concentrations so that the in vivo levels would have been higher, perhaps much higher, than those measured. In addition, we did not measure the metabolites of bupropion, some of which retain pharmacological activity (although they are less potent than bupropion itself) and concentrations of which can be many times higher than that of bupropion itself [46]. As a result of this uncertainty we can draw no conclusions about the overall toxicity of bupropion at therapeutic levels.

To our knowledge, there is no information on the blood/plasma ratio of bupropion. Thus, the comparison of our results with the therapeutic concentration in living individuals only provides suggestive information. Nevertheless, the median measured postmortem blood concentration for all bupropion positive cases in our study $(0.69 \mathrm{mg} / \mathrm{L})$ was many times above the upper limit of the normal plasma concentration range for treatment of depression $(0.1 \mathrm{mg} / \mathrm{L})$ and we assume that levels at time of death were significantly higher. Therefore, any role of bupropion in fatalities could be due to massive overdose, deliberate or accidental.

Despite the limitations described above, the data reported here demonstrate an association between high postmortem level of bupropion and suicides. As with illegal stimulant drugs, high doses of bupropion could promote suicidal behaviour, perhaps because of the impaired judgement and lack of critical thinking associated with a stimulant high. Given the high concentrations of bupropion in these postmortem blood samples, and the probability that levels at the time of death were even higher, the observed association with suicide is likely primarily with overdoses rather than therapeutic levels. Since bupropion may be the most appropriate choice of antidepressant for a particular patient, further studies are needed in order to confirm and better understand the relationship between bupropion overdose and suicide so as to ensure patient safety. Also of importance for future studies is assessment of the magnitude and character of bupropion abuse which seems to be increasing along with the increase in medical use.

\section{Acknowledgements}

The authors would like to thank Dr Niall Doherty for his invaluable assistance.

Parts of this study were presented as a poster presentation at the annual meeting of the International Association of Forensic Toxicologists (TIAFT) in Florence, Italy in September 2015.

\section{References}

1] T.E. Wilens, B.R. Haight, J.P. Horrigan, JJ. Hudziak, N.E. Rosenthal, D.F. Connor et al., Bupropion XL in adults with attention-deficit/hyperactivity disorder: a randomized, placebo-controlled study, Biol. Psychiatry 57 (2005) 793-801.

[2] G.I. Papakostas, D.J. Nutt, L.A. Hallett, V.L. Tucker, A. Krishen, M. Fava, Resolution of sleepiness and fatigue in major depressive disorder: a comparison of bupropion and the selective serotonin reuptake inhibitors, Biol. Psychiatry 60 (2006) 1350-1355.

[3] B.J. Rounsaville, Treatment of cocaine dependence and depression, Biol. Psychiatry 56 (2004) 803-809.

[4] M. Fava, A.J. Rush, M.E. Thase, A. Clayton, S.M. Stahl, J.F. Pradko, et al., 15 Years of clinical experience with bupropion $\mathrm{HCl}$ : from bupropion to bupropion SR to bupropion XL, Prim. Care Companion J. Clin. Psychiatry 7 (2005) 106-113.

[5] P. Hsyu, A. Singh, T.D. Giargiari, J.A. Dunn, J.A. Ascher, J.A. Johnston, Pharmacokinetics of bupropion and its metabolites in cigarette smokers versus nonsmokers, J. Clin. Pharmacol. 37 (1997) 737-743.

[6] S.C. Laizure, C.L. DeVane, Stability of bupropion and its major metabolites in human plasma, Ther. Drug Monit. 7 (1985) 447-450.

[7] P. Jain, N. Paliwal, N. Dubey, S. Sharma, B. Singh, Liquid chromatography tandem mass spectrometry method for quantification of buproprion and hydroxy buproprion in human plasma and its application to bioequivalence study, Int. J. Drug Dev. Res. 4 (2012) 381-392.

[8] Prescribing Information of Wellbutrin, Glaxo Wellcome, 2012, available at: http:// www.accessdata.fda.gov/drugsatfda_docs/label/2013/ 018644s045,020358s052lbl.pdf (accessed 04.12.15).

[9] J.A. Johnston, J. Ascher, R. Leadbetter, V.D. Schmith, D.K. Patel, M. Durcan, et al., Pharmacokinetic optimisation of sustained-release bupropion for smoking cessation, Drugs 62 (2002) 11-24.

[10] J.D. Griffith, J. Carranza, C. Griffith, L.L. Miller, Bupropion: clinical assay for amphetamine-like abuse potential, J. Clin. Psychiatry 44 (1983) 206-208.

[11] G. Zernig, H. De Wit, S. Telser, M. Nienhusmeier, G. Wakonigg, K. Sturm, et al., Subjective effects of slow-release bupropion versus caffeine as determined in a quasi-naturalistic setting, Pharmacology 70 (2004) 206-215.

[12] J. McCormick, Recreational bupropion abuse in a teenager, Br. J. Clin. Pharmacol. 53 (2002), 214-214

[13] B. Langguth, G. Hajak, M. Landgrebe, W. Unglaub, Abuse potential of bupropion nasal insufflation: a case report, J. Clin. Psychopharmacol. 29 (2009) 618-619.

[14] D. Kim, B. Steinhart, Seizures induced by recreational abuse of bupropion tablets via nasal insufflation, CJEM 12 (2010) 158-161.

[15] D. Phillips, Wellbutrin $\mathbb{R}$ : misuse and abuse by incarcerated individuals, J. Addict. Nurs. 23 (2012) 65-69.

[16] R.R. Reeves, M.E. Ladner, Additional evidence of the abuse potential of bupropion, J. Clin. Psychopharmacol. 33 (2013) 584-585.

[17] G. Yoon, J. Westermeyer, Intranasal bupropion abuse, Am. J. Addict. 22 (2013), $180-180$

[18] K. Oppek, G. Koller, A. Zwergal, O. Pogarell, Intravenous administration and abuse of bupropion: a case report and a review of the literature, J. Addict. Med. 8 (2014) $290-293$. 
[19] N. Stall, J. Godwin, Bupropion abuse and overdose, CMAJ 186 (2014) 1015.

[20] A. Rostas, U. Wolf, Bupropion abuse resulting in hypomania in a geriatric amphetamine user: a case report, Am. J. Addict. 24 (2015) 765-766.

[21] Organisation of Economic Co-operation and Development, Health at a Glance 2013: OECD Indicators, 2013, Nov 21, http://dx.doi.org/10.1787/health_glance2013-en.

[22] J. Neeleman, S. Wessely, M. Wadsworth, Predictors of suicide, accidental death, and premature natural death in a general-population birth cohort, Lancet 351 (1998) 93-97.

[23] J. Ludwig, D.E. Marcotte, Anti-depressants, suicide, and drug regulation, J. Policy Anal. Manag. 24 (2005) 249-272.

[24] R.D. Gibbons, K. Hur, D.K. Bhaumik, J.J. Mann, The relationship between antidepressant medication use and rate of suicide, Arch. Gen. Psychiatry 62 (2005) 165-172.

[25] A. Carlsten, M. Waern, A. Ekedahl, J. Ranstam, Antidepressant medication and suicide in Sweden, Pharmacoepidemiol. Drug Saf. 10 (2001) 525-530.

[26] G.E. Simon, J. Savarino, B. Operskalski, P.S. Wang, Suicide risk during antidepressant treatment, Am. J. Psychiatry 163 (2006) 41-47.

[27] A. Fugelstad, A. Annell, J. Rajs, G. Agren, Mortality and causes and manner of death among drug addicts in Stockholm during the period 1981-1992, Acta Psychiatr. Scand. 96 (1997) 169-175.

[28] A.K. Jönsson, P. Holmgren, H. Druid, J. Ahlner, Cause of death and drug use pattern in deceased drug addicts in Sweden, 2002-2003, Forensic Sci. Int. 169 (2007) 101-107.

[29] S. Elliott, J. Evans, A 3-year review of new psychoactive substances in casework, Forensic Sci. Int. 243 (2014) 55-60.

[30] P. Kriikku, J. Rintatalo, K. Pihlainen, J. Hurme, I. Ojanperä, The effect of banning MDPV on the incidence of MDPV-positive findings among users of illegal drugs and on court decisions in traffic cases in Finland, Int. J. Legal Med. (2015) 1-9.

[31] US Food and Drug Administration, Center for Drug Evaluation and Research: FDA public health advisory: Worsening depression and suicidality in patients being treated with antidepressant medications, March 22, 2004. http://www.fda.gov/ Drugs/DrugSafety/PostmarketDrugSafetyInformationforPatientsandProviders/ ucm161696.htm (accessed 02.06.16).

[32] US Food and Drug Administration, The smoking cessation aids varenicline (marketed as Chantix) and bupropion (marketed as Zyban and generics): suicidal ideation and behavior, Drug Safety Newsletter (FDA) 2 (2009).
[33] Act of the inquest into the cause of death (Laki kuolemansyyn selvittämisestä 459/1973).

[34] M. Sundström, A. Pelander, V. Angerer, M. Hutter, S. Kneisel, I. Ojanperä, A highsensitivity ultra-high performance liquid chromatography/high-resolution timeof-flight mass spectrometry (UHPLC-HR-TOFMS) method for screening synthetic cannabinoids and other drugs of abuse in urine, Anal. Bioanal. Chem. 405 (2013) 8463-8474.

[35] M. Sundström, A. Pelander, K. Simojoki, I. Ojanperä, Patterns of drug abuse among drug users with regular and irregular attendance for treatment as detected by comprehensive UHPLC-HR-TOF-MS, Drug Test. Anal. 8 (2016) 39-45.

[36] I. Rasanen, J. Kontinen, I. Nokua, E. Ojanperä, Vuori, Precise gas chromatography with retention time locking in comprehensive toxicological screening for drugs in blood, J. Chromatogr. B 788 (2003) 243-250.

[37] P. Lunetta, A. Lounamaa, S. Sihvonen, Surveillance of injury-related deaths: medicolegal autopsy rates and trends in Finland, Inj. Prev. 13 (2007) 282-284.

[38] P. Heikman, M. Häkkinen, I. Ojanperä, Myös masennuslääkkeitä väärinkäytetään (Antidepressant are also being abused), Suomen Lääkärilehti 48 (2015) 3263 (in Finnish).

[39] H.A. Spiller, E. Bottei, L. Kalin, Fatal bupropion overdose with post mortem blood concentrations, Forensic Sci. Med. Pathol. 4 (2008) 47-50.

[40] T.P. Rohrig, N.G. Ray, Tissue distribution of bupropion in a fatal overdose, J. Anal Toxicol. 16 (1992) 343-345.

[41] V. Ramcharitar, B.S. Levine, B.A. Goldberger, Y.H. Caplan, Bupropion and alcohol fatal intoxication: case report, Forensic Sci. Int. 56 (1992) 151-156.

[42] P.N. Friel, B.K. Logan, C.L. Fligner, Three fatal drug overdoses involving bupropion, J. Anal. Toxicol. 17 (1993) 436-438.

[43] C.R. Harris, J. Gualtieri, G. Stark, Fatal bupropion overdose, Clin. Toxicol. 35 (1997) 321-324.

[44] M.G. Belson, T.R. Kelley, Bupropion exposures: clinical manifestations and medical outcome, J. Emerg. Med. 23 (2002) 223-230.

[45] P.M. O'Byrne, R. Williams, J.J. Walsh, J.F. Gilmer, The aqueous stability of bupropion, J. Pharm. Biomed. Anal. 53 (2010) 376-381.

[46] J.W. Jefferson, J.F. Pradko, K.T. Muir, Bupropion for major depressive disorder: pharmacokinetic and formulation considerations, Clin. Ther. 27 (2005) 1685-1695. 